\title{
Midstream Modulation of Technology: Governance From Within
}

\author{
Erik Fisher \\ Arizona State University \\ Roop L. Mahajan \\ Virginia Polytechnic Institute and State University \\ Carl Mitcham \\ Colorado School of Mines
}

Public "upstream engagement" and other approaches to the social control of technology are currently receiving international attention in policy discourses around emerging technologies such as nanotechnology. To the extent that such approaches hold implications for research and development $(R \& D)$ activities, the distinct participation of scientists and engineers is required. The capacity of technoscientists to broaden the influences on $R \& D$ activities, however, implies that they conduct $R \& D$ differently. This article discusses the possibility for more reflexive participation by scientists and engineers in the internal governance of technology development. It reviews various historical attempts to govern technoscience and introduces the concept of midstream modulation, through which scientists and engineers, ideally in concert with others, bring societal considerations to bear on their work.

Keywords: governance; midstream; modulation; upstream engagement; policy; social control; social shaping

$\mathrm{T}$ here is growing anticipation among policy makers, scientists, and scholars that the confluence of a few powerful technologies-nanotechnology, biotechnology, information technology, and cognitive technology-is poised to usher in a new age of rapid developments that may revolutionize countless aspects of our lives, including health care, communication, national security, consumer products, and transportation, to name only a few (Roco \& Bainbridge, 2002). As with prior emerging and converging technologies, the potential for benefits-such as increased gas mileage from lighter automobiles and increased processor speeds from smaller computer components-appears to be intermingled with the potential for disruptions of established societal, natural, and technological systems. As is being increasingly recognized, potential public concern over the implications of these technologies for a range of issues, including the environment, quality of life, and human dignity, lurks in the background of projected innovation trajectories. As a result, a rising chorus of voices in policy circles has suggested that the development of these converging technologies must be undertaken with due consideration to societal and ethical concerns.

Such concerns have traditionally been addressed both "downstream" of technological development, for instance by regulations and market mechanisms, as well as "upstream," for instance by research policy and technology assessment (TA). Although these preand post-research and development (R\&D) stages are crucial social and policy intervention points, the R\&D stage itself constitutes a largely overlooked opportunity for influencing technological development in accordance with complex sociotechnical

AUTHORS' NOTE: Thanks to Roger Pielke Jr., Arie Rip, Daniel Sarewitz, and Dirk Stemerding for reading and commenting on earlier versions of this article. Thanks also to Ami Nacu-Schmidt for her work on the flow diagram in this article. This material is based on work supported by the National Science Foundation (Grant 0531194).

Bulletin of Science, Technology \& Society Vol. 26, No. 6, December 2006, 485-496

DOI: $10.1177 / 0270467606295402$

Copyright $\odot 2006$ Sage Publications 
dynamics. To illustrate, we consider various governance approaches to technology, including what has recently been termed public upstream engagement. Upstream engagement seeks to improve traditional policy approaches but, to realize its goals, requires a complementary "midstream" integration of technical and societal elements.

Historically, there has been an institutionalized disconnect between efforts to promote technoscience on one hand and to control it on the other. This "twotrack regime of managing technology in society" ensures that "regulatory agencies [are] separate from technology-promotional agencies" (Schot \& Rip, 1997, p. 264) and discourages broader societal considerations from being integrated into and potentially influencing R\&D. After a brief review of historical attempts to govern science and technology, we consider more recent attempts to bridge the gap between the promotion and control of technological innovation. We discuss conceptual and practical dimensions of the midstream modulation of technological trajectories as informed by an interdisciplinary body of literature and our own efforts at sociotechnical integration within an engineering research laboratory. We reflect on challenges and opportunities for enhancing the participation of scientists and engineers in the larger task of shaping technoscience given an increasing awareness of how societal concerns can affect innovation enterprises.

\section{Brief History of Regulation and Control}

The modern world is defined by the scientific and industrial revolutions of the 17th and 18th centuries. Yet already in the 18th and 19th centuries, these revolutions in knowledge and artifact production were argued by Romantic and socialist critics to be something less than unqualified benefits (Mitcham, 1994b). Ever since, a major approach to reform has sought to enlarge the social control of technology, whether through indirect public engagement or through formal governance. Such external efforts have sought to delimit the power of the few with their restricted interests and enhance the participation (or at least representation) of the many who were affected by scientific and technological change (Mitcham, 1999).

The Romantic criticism of science and technology is easily represented by the poetry of William Blake (1757 to 1827). In opposition to science, Blake presented "The Atoms of Democritus / And Newton's Particles of Light" as but "sands upon the Red Sea shore / Where Israel's tents do shine so bright"; in opposition to technology, Blake bemoaned the "dark Satanic mills" of industrialization that were obstructing the building of "the New Jerusalem" "in England's green and pleasant land." However, not all early opposition to advancing technologies proceeded from such philosophical principles. The motives of the Luddites, who sabotaged textile machines to protect their jobs in the early 1800 s, were inspired by economic and political interests (Schot \& Rip, 1997; Thompson, 1968) rather than "antitechnology" aesthetic and metaphysical values.

During the next 200 years, numerous historical events, agitated by a variety of interests and perspectives, reflected the effort to formally broaden the external influences over science and technology. Labor movement demands for safer working conditions and machinery in the early 19th century; the public health movement of the mid-19th century; and the various efforts that led during the late 19th and early 20th centuries to the establishment of agencies to regulate transportation networks, building designs, and the sale of foods and drugs are all instances of the movement toward broader social sway over the processes and end products of technology. Whether through activism or through formal regulation, such efforts were largely reactive, in that they responded to existing undesirable consequences, and external, because they emerged from and were enforced by social and governmental outsiders. The only real participation required by scientists and engineers under these conditions was that of compliance to technical rules and standards. However, with an increase in the pace, scope, and reach of technoscience, the variety of participants who sought to more broadly influence its deployment also increased.

For instance, in the immediate aftermath of World War II, the atrocities of German and Japanese medical experimentation on human subjects led to creation of the Nuremberg Code requirements of free and informed consent for all human participants in biomedical research. The 1964 Helsinki Declaration of the World Medical Association strengthened this principle, and in 1991 the declaration became the basis for U.S. Code (the Federal Policy for Protection of Human Subjects), in principle bridging internal and external governance. During the 1950s and 1960s, issues of governance took on further urgency under the stimulus first of nuclear weapons and then of environmental pollution. In 1959, the scientist and novelist C. P. Snow at once diagnosed the problem in The Two Cultures and the Scientific Revolution and claimed that the technoscientific community was better able to address 
it than those literary intellectuals who criticized science and technology. Scarcely 3 years after Snow, the biologist and nature writer Rachel Carson (1962) in Silent Spring argued in a restatement of the Romantic criticism that science itself needed to be reformed. Remarkably, however, in some sense, Snow and Carson tended to agree that it was from within the scientific and technical community that the solutions to the new problems of population, the gap between rich and poor, nuclear weapons, and environmental pollution would be developed.

In fact, a significant minority of the efforts aimed at governing sociotechnical outcomes were internally conceived. The temporary ban on recombinant DNA research in the mid-1970s was an instance of promotion and control functions converging, albeit in a radical form, with control eclipsing promotion. There exist as well a number of other 20th-century instances of "professional scientific idealism" in which criticism of technoscience was articulated by scientific associations. These include the Pugwash movement and the Committee on Scientific Freedom and Responsibility of the American Association for the Advancement of Science (Mitcham, 2003b). Internal attempts at selfregulation often required external coordination, such as oversight and enforcement, thus giving rise to what has been termed "coresponsibility" (Mitcham, 2003a). Carson's (1962) ideas, for instance, were moved forward primarily by the establishment of the Environmental Protection Agency. And although the Committee on Scientific Freedom and Responsibility argued for the protection of whistle-blowers, whistleblowers themselves would have to rely on various federal and state regulations for actual protection.

\section{TA and Ethical, Legal, and Societal Implications Research}

As issues of participation and governance grew more complex and interactive, so did those of science and technology policy. The mid-20th century saw a new approach emerge, one associated with the term technology assessment (TA), which emphasized research on the "social, ethical, and environmental impacts" of scientific and technological change (Shrader-Frechette, 1995). The intention, as in the founding approach of the U.S. Office of Technology Assessment (1970 to 1994), was to use the resulting knowledge of impact assessment for forecasting and thereby to help legislators decide which technologies should be funded for development or how they might be regulated. The anticipatory nature of TA represents a significant development in the attempt to govern $\mathrm{R} \& \mathrm{D}$, for it supplemented regulation with agenda setting and factored downstream considerations into upstream decision-making contexts.

Such "parliamentary" TA (Van den Ende, Mulder Knot, Moors, \& Vergragt, 1998), however, was limited by the uncertainty associated with initial forecasting and the challenges of regulating technologies after they had been developed. Moreover, it deterministically conceived of R\&D outcomes as technological "impacts" on society, which could then be remedied by direct policy interventions (Rip, 2002). Barriers to the effectiveness of TA thus included the "illusory" nature of predictive certainty as well as the interacting and interdependent "suites of technologies that permeate society along many dimensions" (Sarewitz, 2005). Early forms of TA thus took more societal and policy dynamics into account but nevertheless oversimplified R\&D dynamics and outcomes.

As TA was adopted and considerably adapted around the globe, it underwent changes to more "participatory" and "constructive" forms (Van den Ende et al., 1998), notably the Dutch approach of constructive TA (CTA). CTA, which continues to be practiced, seeks to introduce not just a broader scope of issues into assessment activities but also a more extensive array of participants. Moreover, it seeks to influence not only parliamentary (or upstream) decisions but technological design decisions as well (Rip, Misa, \& Schot, 1995; Schot \& Rip, 1997).

In the early 1990s, the Ethical, Legal, and Societal Implications (ELSI) program of the Human Genome Project became the first U.S. federally funded societal research program to include a self-critical element in the scientific research program that funded it. In this way, ELSI research commenced and was charged to help "forestall adverse effects" of biotechnology (U.S. Senate, Committee on Commerce, Science, and Transportation, 1989), partly through making policy recommendations. In theory, ELSI research extrapolates implications from ongoing or proposed technoscientific research to provide intelligence for upstream policy making and downstream regulation. Although the ELSI program did on occasion influence policy, it has been widely criticized for lacking the capacity to accomplish its charge (Fisher, 2005).

\section{Upstream Engagement}

What has recently been denominated public upstream engagement (e.g., Wilsdon \& Willis, 2004) with science and engineering exemplifies a growing 
focus on more interactive approaches to sciencetechnology-society relations. Through dialogue and other engagement practices, upstream approaches seek to augment traditional communication models so that discourse and learning can flow not only from policy makers, scientists, and engineers to the public but also in the reverse direction. Societal influences are thus meant to help shape technological development trajectories before technological paths build up momentum and become relatively locked in. Such efforts aim at more broadly orchestrated and more effective societal inputs than those used by past attempts to assess, regulate, and direct technology.

The Danish Board of Technology's consensus conferences, which have been practiced since the 1980s, are perhaps the best-known example of public participation in national policy decisions about science and technology. Recently, the language of upstream engagement has emerged internationally in policy discourses, policy measures, and institutions. Public and other forms of participation are gaining credence with policy makers largely because expert-based risk assessment and "deficit" communication approaches have failed to address public concerns regarding emerging technologies (e.g., Wilsdon \& Willis, 2004). For instance, in the preface to a collection of essays published by the Woodrow Wilson International Center for Scholars, David Rejeski (2005) suggested that "the [U.S.] government faces a public that has grown more suspicious of both public and private sector motivations concerning technological advances and a scientific community that remains largely isolated, and often oblivious, to public concerns" (p. 5). Similarly, in the preface to a pamphlet from the U.K. think tank Demos, former House of Lords Select Committee on Science and Technology chairman and 2006 president of the British Association for the Advancement of Science Lord Winston (2005) wrote,

The scientific community once believed it could assuage public concerns over the misuse of science by better communication of the benefits of scientific knowledge. There has been gradual, sometimes grudging, recognition that mere communicationwhilst important—cannot alleviate justifiable anxieties. Now the watchword is "engagement" and with it, "dialogue." The scientific community is beginning to realise, but often reluctantly accept, that we scientists need to take greater notice of public concerns, and relate and react to them. (p. 12)

James Wilsdon (2005) further chronicled a recent "wave of interest in moving public engagement 'upstream'- to an earlier stage in processes of research and development" (p. 23), and James Wilsdon, Brian Wynne, and Jack Stilgoe (2005) noted that "the language of 'upstream' engagement had started to appear in statements by [the U.K.] government and the Royal Society" (p. 32). Others have traced the engagement concept of "dialogue" to a House of Lords Select Committee on Science and Technology Science and Society (2000) report (cf. Jackson, Barbagallo, \& Haste, 2005) that acknowledged a "need for reform in governing science and technology" (Jasanoff, 2003).

Policy discourse over public concerns is especially prominent regarding nanotechnology, in which both promotion and control efforts are receiving significant attention and appear somewhat to be converging, at least rhetorically. The president of Lux Research Inc., a technology research and consultation firm, has stated before the U.S. House Committee on Science that "responsible development of nanotechnology-to ensure that the U.S. obtains the full benefits of nanotechnology applications-requires addressing both real and perceptual risks" (Nordan, 2005, p. 4). In 2003, U.S. federal legislation mandated several strategies for addressing societal concerns about nanotechnology, including the use of citizen panels (21st Century Nanotechnology Research and Development Act, 2003; cf. Fisher \& Mahajan, 2006a). Notably, the strategies are intended to "influence the direction of research" (U.S. House of Representatives, Committee on Science, 2003). In 2005, the legislation resulted in two national centers for nanotechnology in society, one of which, at Arizona State University, will enable sustained interactions among social scientists, engineers, natural scientists, and members of the public. (The other center is at the University of California, Santa Barbara.) One of the core undertakings of the Center for Nanotechnology in Society at Arizona State University will be a national citizen technology forum. In the United Kingdom, Wilsdon et al. (2005) listed three separate government sponsored programs pertaining to nanotechnology that are under way, all of which focus on upstream public engagement.

The immediate objective of upstream engagement and similar participatory activities is to "shape the trajectory of technological development" (Wilsdon, 2005) by means of "improved social intelligence and better decision-making" (Wilsdon et al., 2005, p. 19). The ultimate goal of public participation is to improve sociotechnical outcomes (Guston, 2004). The justification for including members of the lay public in dialogues about science and technology 
decisions depends on how the problem is defined. From a technoscience-promotional perspective, the problem is a potential lack of public trust and acceptance, which could jeopardize research funding and commercialization, and thus incorporating public perspectives is if nothing else a matter of enlightened self-interest (Rip, 2002). Meanwhile, social control efforts are aimed at mitigating potentially undesirable consequences (whether intended or unintended) and maximizing public interests through the exercise of choice and the distribution of power (Sclove, 1995). Thus, what promotion-minded perspectives see as a "business proposition" (Bonds, 2003) social control-minded perspectives see as "everyone's business" (Kass, 2006). In either case, inputting a broader set of perspectives in technology decision contexts may increase the likelihood of more robust decisions and, the hope is, more desirable outcomes (Guston, 2004; see Rip \& Schot, 1997; Sarewitz, 2005).

Like TA and ELSI programs, upstream approaches emphasize the early consideration of sociotechnical implications. Yet unlike parliamentary forms of TA and ELSI programs, public engagement is based on the premise that social processes, which include normative assumptions and agendas, occur throughout technological development trajectories, including the otherwise technical R\&D stages, and can influence outcomes accordingly (see Bijker, Hughes, \& Pinch, 1989; Bucciarelli, 1994; Winner, 1986). Public engagement is therefore meant to more collectively shape technological development trajectories rather than to more simplistically direct and control them. The concept of shaping rather than controlling sociotechnical phenomena takes into account that what appear to be discrete causes of technological development are subject to multiple interacting influences that continuously feed back on one another. The concept of a technological development trajectory allows that multiple influences affect and are affected by sociotechnical phenomena while still preserving the importance of the various functions and timings of these influences.

We may thus liken the concept of a technological development trajectory to a decision process, the stages of which may be characterized in terms of authorization, implementation, and adoption, any of which may occur by various mechanisms and matters of degree. For those seeking to influence the evolution of technological trajectories, potential intervention points include both policy processes and laboratory processes (Wilsdon, 2005; Wilsdon et al., 2005). As Phil Macnaughten, Matthew Kearnes, and Wynne (2005) observed, "commitments to 'upstream' public engagement in processes of scientifictechnological innovation are a significant shift in publicpolicy discourse, and raise many unresolved questions for . . . science itself" (p. 277). Whether directly or indirectly, then, the goals of upstream engagement encompass not only those who decide policies but also those who conduct and perform R\&D.

\section{Implications for the Technoscientific Community}

Public engagement seeks to encourage scientists and engineers to go beyond their roles as experts: In interacting with lay publics and others, "citizen scientists" (Wilsdon et al., 2005) can broaden their social and ethical reflections through exposure to additional perspectives. Yet the technoscientific community is implicated in other ways as well, because producing different technologies implies to some extent that technologies be produced differently. In other words, shaping technological trajectories will at some point include shaping the very $R \& D$ processes that help characterize them. This prospect touches on the expertise of scientists and engineers, for whom shaping $R \& D$ trajectories from the inside is ultimately a matter of self-governance. As we have found, however, multiple factors may contribute to reluctance on the part of scientists and engineers to engage in societal criticism of their work, especially if that criticism does not seem to provide immediate practical insights for making decisions differently.

If scientists and engineers are to develop the capabilities to more broadly influence technological development trajectories, let alone exercise those capabilities, they may require significantly different skills and learning opportunities than those provided by interactions with the public. Whatever is learned from engagement with the public would presumably be applied during periods and activities that, to a large extent, will by necessity exclude public participation. Moreover, these activities will take place amid highly constrained, complex, and distributed environments (e.g., Rip, 2002, 2006), and it can often be unclear how societal considerations and perspectives can be directly brought to bear on bench work. Engineers, for instance, routinely exclude broader considerations from their cogitations to make them manageable (Mitcham, 1994a; Newberry, in press). In fact, engineering education is largely premised on this exclusion (Bucciarelli, 1994).

Although public engagement methods imply the participation of scientists and engineers as citizens, 
public engagement objectives imply their participation as scientists and engineers. Internal efforts to integrate societal considerations into $R \& D$ would need to take into account existing $R \& D$ contexts, whether national, industrial, or academic. Effective technology-shaping strategies would need to support the capacity of scientists and engineers to accommodate, assist, and in many cases initiate changes from within. As a complement - and in some cases even as a practical alternative - to external engagement, then, stands the challenge of internally shaping R\&D trajectories via technical expertise and with a view to societal considerations. Currently, there is little by way of policy precedents (Fisher \& Mahajan, 2006a) or social research (Macnaughten et al., 2005) that points toward precisely how to do this.

In concert with the roles of publics and social scientists in facilitating the social shaping of technological trajectories, it is important to gain a better understanding of the roles implied for scientists and engineers, whose technical activities themselves would presumably be affected. Given the apparent incongruity of mainstream science and engineering work with respect to the idea of more broadly shaping $\mathrm{R} \& \mathrm{D}$ trajectories, conceptually recasting the somewhat invisible and often "back-boxed" efforts of scientists and engineers may be a helpful starting point. According to Macnaughten et al. (2005), sociotechnical consequences can occur (and people operate) "upstream, downstream, or somewhere in between." We are interested in the stage somewhere in between.

\section{Introducing the Midstream}

The stream metaphor has its limitations. Those who champion upstream engagement (e.g., Wilsdon, 2005; Wilsdon et al., 2005) are understandably at pains to avoid legitimizing the so-called linear model, a widely influential yet highly problematic ideal that posits an inevitable flow in this order: research funding, basic research, applied research, technological development, and societal benefits. The linear model has been deservedly criticized for its axiomatic distinction between basic and applied research (Kitcher, 2001) as well as for its tenet that funding basic research is therefore both necessary and sufficient for beneficial sociotechnical outcomes (Jasanoff, 2003, 2005; Pielke \& Byerly, 1998). The reality is that research policy and funding are often influenced by ongoing research, just as applied research can lead to basic research, both of which can be influenced by continual societal influences (Sarewitz, 1996). Moreover, numerous federal science policies appear aimed at "enforcing linearity" (Mitcham \& Frodeman, 2004).

Clearly, neither the linear model nor a more robust stream metaphor-with eddies, back currents, eroding banks, shifting depths, and whatnot-is a fully accurate model of the complex relationships among policy, science, engineering, and society. That said, the stream metaphor does retain valuable information: Research funding is a principal influence on $\mathrm{R} \& \mathrm{D}$, and developed technological systems and artifacts do contribute to end-user outcomes. We use the metaphor to suggest a coherent relationship among the overlapping and fluid stages of research policy, R\&D work, and end use.

As hitherto used, the image of upstream engagement has been from the perspective of downstream public recipients of technoscientific output who are typically external to its workings. Another, complementary perspective is that of the technoscientific community, which operates in the midst of technological trajectory development. From this vantage point, sociotechnical outcomes are indeed downstream occurrences, whereas upstream activities are those of policy and decision makers who determine budgets, set agendas, and articulate high-level research priorities.

Stabilizing the stream metaphor around this vantage point allows one to characterize the main stages of technoscientific governance as upstream, midstream, and downstream activities. Likening these stages to those of an overall distributed decision process, upstream activities are recast as policy processes that authorize R\&D, midstream activities as technoscientific processes that implement $R \& D$, and downstream activities as end-user processes that adopt (here, a concept that includes acceptance, modification, and rejection) R\&D outputs. As stated, these three stages feed back into one another and are not always temporally coherent. Nevertheless, each stage can be treated as a decision process in and of itself, so that each stage can be further divided into substages that are likewise conceptually but not necessarily temporally distinct. For instance, $R \& D$ consists of scientific research, engineering research, product design, product development, and similar interacting yet conceptually distinct decision functions.

Viewed this way, the midstream corresponds to the implementation stage of a large, distributed, and dynamic decision process. For simplicity, upstream decisions may be characterized as determining what research to authorize, midstream decisions as determining how to implement R\&D agendas, and downstream decisions as determining whether to adopt 
developed technologies. As such, midstream decisions may not seem to carry the same weight or visibility as those made during the upstream stage. Still, they present a unique and largely overlooked opportunity for governance. As do all process stages, the midstream involves subprocesses that in turn contain nested what, how, and whether decisions. Midstream deliberations are not fully constrained by upstream agendas, nor are they limited to a purely instrumental approach to their implementation. As Johan Schot (1992) stated, during R\&D "choices are constantly being made about the form, the function, and the use of [a given] technology" (p. 37). To the extent that flexibility exists within the midstream-whether in the form of individual choices and group decisions or more collective behaviors, functions, and arrangements-there arise, in theory, possibilities for the midstream modulation of technological development trajectories.

The suggested taxonomy may be conceptualized in a flow diagram (see Figure 1). As the recursive arrows indicate, the stream metaphor need not codify the so-called linear model of influence from science to society, because there are multiple feedback loops that complicate the primary direction of flow.

The midstream takes on more recognizable significance given the dual challenges of a well-known dilemma: Upstream agenda setting often occurs too early and downstream regulation, market selection, and use often occur too late to be effective (Collingridge, 1981; Rip, 2002; Rip \& Kemp, 1998; Wilsdon \& Willis, 2004). Although R\&D is framed by upstream decisions and investments, as it evolves, results are generated and interpreted, constraints are encountered, specific applications are more concretely and newly envisioned, and objectives are adjusted and readjusted. The course of such evolutions and developments cannot be accurately predicted during upstream stages any more than they can be effectively regulated during downstream stages. Thus, the midstream suggests opportunities for influencing trajectories more concretely than upstream and more flexibly than downstream stages.

Given the nature of R\&D dynamics, in which intentional efforts can be futile and counterproductive and "distributed coherence" tends toward technological momentum, irreversibilities, and path dependencies (Rip, 2006), the challenges for shaping technoscientific processes and activities in accordance with broader societal considerations are immense. Midstream activities are considerably constrained by physical limitations, resources, and available expertise, not to mention institutional and organizational pressures and interests.

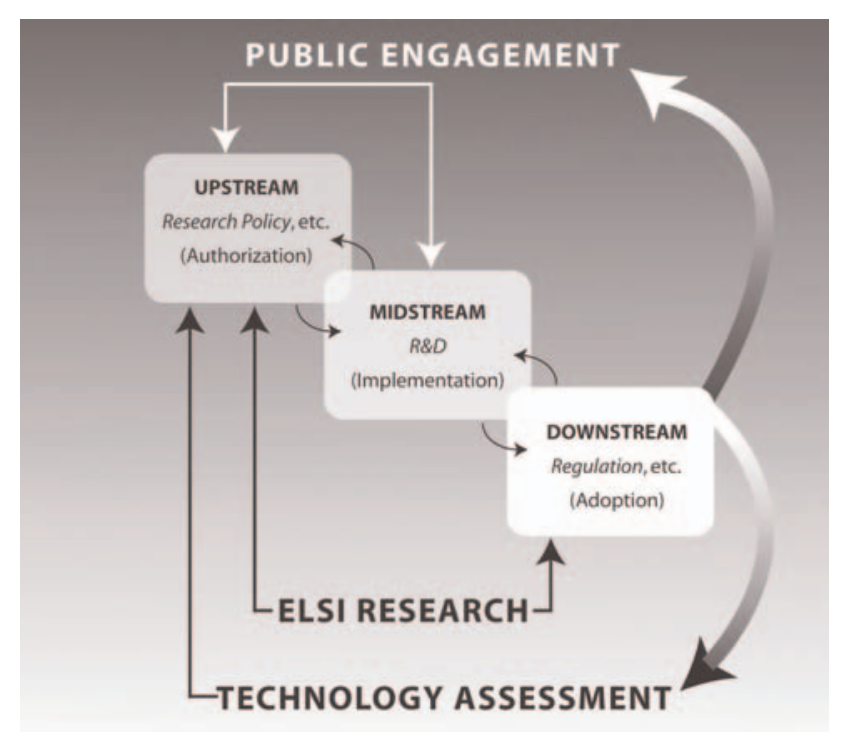

Figure 1. Science and Technology Governance Stages

Note: ELSI = Ethical, Legal, and Societal Implications; R\&D = research and development.

The challenge is further signified by the fact that, unlike upstream and downstream stages, there are few policy mechanisms for the midstream that are aimed at anticipating end-user outcomes. Standards, rules, and regulations, which often are directives from upstream or downstream, are largely static, can become outdated, and can fail to apply clearly to dynamic and changing R\&D processes and contexts (e.g., Vincenti, 1990). It is no surprise that R\&D remains largely conceptualized as the instrument of promotion, with control almost by definition seen as externally orchestrated, even when scientists and engineers themselves initiate or devise it.

\section{Modulating the Midstream}

The modulation of ongoing sociotechnical processes is a concept that was developed as an alternative to top-down policy directives and intentionbased interventions, insofar as these can fail to achieve desired ends. Arie Rip has introduced and used the concept in relation to CTA (Schot \& Rip, 1997), innovation and technological change (Rip \& Kemp, 1998), coevolutionary theories of technological change (e.g., Rip, 2002) and reflexive governance (Rip, 2006). With respect to science and technology, their "quasi-autonomous dynamics ... appear to be so strong that governance actors cannot do much more than try to modulate what is going on anyway" (Rip, 2006); thus, "modulation of ongoing processes 
rather than forceful shaping is the enlightened approach" (Rip, 2002, p. 10). Applied to the context of the midstream, the concept of modulation can help guide internal attempts to conduct and implement $\mathrm{R} \& \mathrm{D}$ with an eye toward subtly and creatively shifting ongoing, nested interactions among technoscientific actors and networks. Midstream modulation therefore denotes the alteration of R\&D activities and processes in accordance both with existing constraints and dynamics but also with broader societal goals, considerations, or influences. As such, it integrates the otherwise separate functions of promotion and control in relation to one another.

Tools, strategies, and principles for modulating sociotechnical processes already exist and can be adapted for application to R\&D processes and activities "from within." However, a central challenge to midstream modulation is preparing the ground for the effective application of modulation strategies. To a significant extent, modulation capacities would need to be conceptualized and developed locally and from the bottom up to ensure that methods are neither unproductive, tedious, nor counterproductive - or are seen to be so. Technoscientific capacity for midstream modulation must take root in operative local and distributed conditions, constraints, and capabilities. A key to capacity building is for actors to become attentive to the nested processes, structures, interactions, and interdependencies, both immediate and more removed, within which they operate. Such attentiveness leads to what is termed here "reflexive awareness." As Rip (2002) stated, "it is clearly important to link concrete change action with larger patterns in the overall development of technology and society" (p. 2), because productive modulation "requires understanding of the nature and dynamics of the processes including [one's] own position and role in them" (p. 4). For technoscientific participants, reflexive awareness can be related to societal, collective, group, and individual levels.

Engagement with members of the public, social scientists, and others can no doubt build awareness of broader societal values, contexts, and interactions. Such awareness is obviously important; unfortunately, it may find little traction for practical application if complementary forms of awareness are not cultivated and engaged. To ascertain what may be possible in response to broader considerations, something like a "recognition of the emergence and effect of [technoscientific] repertoires and regimes" (Rip, 2002, p. 2) may be essential for individual and collective level shaping to occur. Regimes, repertoires, "technological suites" (Sarewitz, 2005), and their coevolutions emerge largely from collective and distributed actions and interactions of R\&D actors. In turn, collective actions emerge from smaller scale networking and small groups, which are ultimately affected by the "everyday" practices and interactions of individuals.

As a matter of course, modulation will occur at all these levels, whether consciously or not. Insofar as responsive capacity is predicated on what actors know best, a program for midstream modulation could begin largely through reflection on the de facto modulation that is already going on, to give rise to reflexive modulation. Yet as Schot and Rip (1997) stated, "modulation of ongoing processes is an empty phrase if one does not specify the goals or criteria that guide modulation activities" (p. 257). Accordingly, reflexive modulation would ideally give rise to the possibility for goal-directed modulation (see Kemp, Parto, \& Gibson, 2005), whether goals are explicit or implicit and initiated from within or without.

Formal or, better, semiformal representation of participants' own activities and processes can encourage reflexive awareness. For instance, the use of coevolutionary conceptions can increase awareness of being part of a broader system (Rip, 2002). Coevolutionary perspectives could be used to generate additional technological variations, in anticipation of competing in broader sociotechnical selection environments. In another case, undergraduate engineering students have been shown to gain conceptual facility in both technical writing and in product design processes by representing such processes as a series of iterative steps (Fisher \& Benassi, 2003). Additionally, experiences integrating societal considerations into an academic research laboratory setting suggest that such reflection may in fact help research planning and stimulate research creativity (Fisher \& Mahajan, 2006b). Modulation of this kind happens in the lab regularly as a result of less structured feedback that occurs in research group meetings and more generally through peer review. Reflecting on existing thought patterns and structures may take time at first but can add value to what is already happening in more ways than one.

Enhancing reflexive awareness may not lead to clear instances of things done differently, but this is not the immediate objective. Rather, building awareness around ongoing dynamic processes and one's place within them is a logical precondition to doing things "differently," which is the general task and challenge (cf. Bijker, 1995; Bucciarelli, 1994; Latour, 1987). This type of bottom-up approach has the advantage of beginning from what is given in the minds of technoscientific agents and can be phrased in terms of aiding 
existing goals and enhancing promotion activities. From this as a starting point, the possibility of more collective goal-directed modulation can emerge, or at least be conceptualized. It is important to note that although midstream modulators by and large consist of social factors, the dynamics of technology development trajectories are neither socially (Law, 1987) nor technologically (cf. Schot, 1992) deterministic, for the (often limited) ability of actors to affect changes will be constrained by physical as well as social and cognitive factors. Although opportunities for changing trajectories may in fact be relatively few, especially during predesign stages, opportunities for enhancing reflexive awareness may abound.

\section{Strategies and Precursors}

At the more collective level, existing and institutionalized strategies can be adapted and used by managers, administrators, research group leaders, and others. Schot and Rip (1997) cite the instance of "simultaneous engineering," which invites comparison with the suite of "design for" industrial approaches (e.g., design for manufacturing, design for the environment). Including additional research project objectives or design specifications, or adapting or developing process and product standards and protocols builds on established practices and approaches. Experience suggests that the emphasis on using such tools should be balanced by attending to the conditions that may allow them to be developed and adopted from within. Furthermore, a productive distinction can be made between strategies that open up new options, alternatives, links, and path-shaping differences and those that close down research, design, and development by adding additional constraints.

Rip (2002, 2006) discussed "generic strategies" that could be used by midstream actors. These include maintaining flexibility, collective alignment, opening up learning spaces and ongoing learning (e.g., of the process of "emerging irreversibilities"), and institutionalizing feedback channels (Rip, 2002). Another strategy, working toward desirable technologies "from the beginning" (Rip, 2002), which includes "backcasting," has been applied within a nanoscale research group context (Gorman, Groves, \& Catalano, 2004). Principles, such as those developed in light of industrial ecology (Allenby \& Richards, 1994; McDonough \& Braungart, 2002) and appropriate technology, can also function as modulators. An adaptation of the Bellmont Report principles, on which human subjects research principles are based, has been suggested for application both in general cases of engineering research and design (Martin \& Schinzinger, 1989), to promote public participation (Shrader-Frechette, 1991), and in relation to nanotechnology (BennettWoods \& Fisher, 2004; cf. Sarewitz \& Woodhouse, 2003). Again, from the standpoint of developing midstream modulation capacity, the point is not which principles should be used or whether any should be used at all but how to get to the stage at which principles and strategies make sense to midstream agents in the first place.

Although there are other strategies, precursors, and potential frameworks for midstream modulation, three additional approaches warrant mention. William Vanderburg (1995) outlined preventive engineering approaches that seek to "adjust engineering theory and practice to create a greater compatibility between technology and its contexts" (p. 155).

We have already referred to CTA, which in taking "technology dynamics" (Schot, 1992) into account is aimed at "broadening design, development, and implementation processes" (Schot \& Rip, 1997). As such, CTA seeks to interface with midstream processes, for example by adding new design criteria to development projects and in general feeding assessment activities into the "actual construction of technology."

Real-time TA (RTTA) constitutes the thematic focus of the Center for Nanotechnology in Society at Arizona State University, funded by the National Science Foundation. Closely in line with several CTA concepts, RTTA endeavors

to build into the $R \& D$ enterprise itself a reflexive capacity that encourages more effective communication among potential stakeholders, elicits more knowledge of evolving stakeholder capabilities, preferences and values, and allows modulation of innovation paths and outcomes in response to ongoing analysis and discourse. (Guston \& Sarewitz, 2002, p. 100)

Notably, RTTA uses aspects of the three main governance approaches discussed in this article: TA and societal implications research, upstream public engagement, and, to some extent, midstream modulation. The latter is exemplified in RTTA because of the way it specifically includes technoscientific participants, not only as experts who inform publics but as potential learners who in turn make choices and whose choices constitute an explicit focus for study, evaluation, and modulation. 


\section{Conclusion}

Effective forms of midstream modulation, to the extent that they are developed in numerous different contexts, will vary extensively and will most likely need to be conceived at the local level and with attention to unique policy, technoscientific, and societal factors. Given that midstream ecologies are composed of numerous sites, capabilities, disciplinary approaches, missions, and functions, the methods adopted may depend on numerous factors, notably the experiences of technoscientific agents themselves. The nature of participation and of particularized modulation goals themselves will affect the generation and selection of strategies and their implementation. It may accordingly make sense to distinguish upstream engagement techniques aimed at policy-making processes from midstream engagement techniques aimed more explicitly at influencing the self-governance of $R \& D$ processes.

Social or policy attempts to influence technological development trajectories, insofar as they implicate science and engineering practices, must at some level begin with such practices. The perspectives and experiences of scientists and engineers and the contexts and constraints of their work are factors that can and need to be taken into account if innovation practices are to be effectively engaged. To this end, case studies that seek to determine both the possibility and the utility of midstream modulation within a specific laboratory context have been undertaken (Fisher \& Mahajan, 2006b). Such efforts are needed to develop both theoretical understanding and practical capacities for midstream agents to productively modulate technological development with respect to societal considerations.

The arguments for midstream modulation should not be taken to imply that only technoscientific insiders can modulate or occasionally steer R\&D. Outsiders are indeed able to influence technological change (Van de Poel, 2000). The efforts of nontechnological experts can be viewed as a form of "repair work elsewhere in the overall system" that will likely constitute key factors for success (Rip, 2006). Just as "there is no single best institutional arrangement for technology analysis" (Rodemeyer, 2005), so no one approach to midstream modulation or, more generally, to the socially reflexive governance and shaping of technological development trajectories is likely to have a durable impact on sociotechnical outcomes without operating in conjunction with others. Accordingly, midstream modulation will work best in tandem with sources of intervention, feedback, and collaboration, such as ELSI research, upstream engagement, CTA, RTTA, and others. Nevertheless, midstream modulation represents a linchpin in the effort to integrate promotion and control and is indispensable if such efforts are to be widespread and lasting.

\section{References}

Allenby, B. R., \& Richards, D. J. (Eds.). (1994). The greening of industrial ecosystems. Washington, DC: National Academies Press.

Bennett-Woods, D., \& Fisher, E. (2004, August). Dilemmas in nanotechnology: Towards a new paradigm for analysis and dialogue. Paper presented at the joint meeting of the European Association for the Study of Science and Technology and the Society of Social Studies of Science, Paris, France.

Bijker, W. (1995). Of bicycles, bakelites, and bulbs: Toward a theory of sociotechnical change. Cambridge, MA: MIT Press.

Bijker, W., Hughes, T., \& Pinch, T. (1989). The social construction of technological systems: New directions in the sociology and history of technology. Cambridge, MA: MIT Press.

Bonds, P. J. (2003, December). Technology administration: Nanotechnology: Economic opportunities, societal and ethical challenges. Keynote address given at NanoCommerce, Chicago.

Bucciarelli, L. L. (1994). Designing engineers. Cambridge, MA: MIT Press.

Carson, R. (1962). Silent spring. Boston: Houghton Mifflin.

Collingridge, D. (1981). The social control of technology. London: Macmillan.

Fisher, E. (2005). Lessons learned from the ELSI program: Planning societal implications research for the National Nanotechnology Program. Technology in Society, 27, 321-328.

Fisher, E., \& Benassi, M. (2003, June). Writing as design: Integrating composition and product design in the undergraduate engineering curriculum. Paper presented at the annual conference of the American Society for Engineering Education, Nashville, TN.

Fisher, E., \& Mahajan, R. L. (2006a). Contradictory intent? U.S. federal legislation on integrating societal concerns into nanotechnology research and development. Science and Public Policy, 33(1), 5-16.

Fisher, E., \& Mahajan, R. L. (2006b, November). Midstream modulation of nanotechnology research in an academic laboratory. Paper presented at the American Society of Mechanical Engineers International Mechanical Engineering Congress and Exposition, Chicago.

Gorman, M. E, Groves, J. F., \& Catalano, R. K. (2004). Societal dimensions of nanotechnology. IEEE Technology and Society Magazine, 23(4), 55-62.

Guston, D. (2004). Forget politicizing science. Let's democratize science! Issues in Science and Technology, 21(1), 1-4.

Guston, D., \& Sarewitz, D. (2002). Real-time technology assessment. Technology in Society, 24(1-2), 93-109.

House of Lords Select Committee on Science and Technology Science and Society. (2000, February 23). Science and technology-Third report: Science and society. London: House of Lords.

Jackson, R., Barbagallo, F., \& Haste, H. (2005). Strengths of public dialogue on science-related issues. Critical Review of International Social and Political Philosophy, 8(3), 349-358. 
Jasanoff, S. (2003). Technologies of humility: Citizen participation in governing science. Minerva, 41, 223-244.

Jasanoff, S. (2005). Technologies of humility: Citizen participation in governing science. In C. Mitcham (Ed.), Encyclopedia of science, technology, and ethics: Vol. 1 (pp. xix-xxvii). Detroit, MI: Macmillan Reference.

Kass, L. R. (2006, January). Forbidding science: Some beginning reflections. Paper presented at the conference Forbidding Science: Balancing Freedom, Innovation, Security \& Precaution, Tempe, AZ.

Kemp, R., Parto, S., \& Gibson, R. B. (2005). Governance for sustainable development: Moving from theory to practice. International Journal of Sustainable Development, 8(1/2), 12-30.

Kitcher, P. (2001). Science, truth, and democracy. New York: Oxford University Press.

Latour, B. (1987). Science in action: How to follow scientists and engineers through society. Cambridge, MA: Harvard University Press.

Law, J. (1987). Technology and heterogeneous engineering: The case of Portuguese expansion. In W. E. Bijker, T. P. Hughes, \& T. Pinch (Eds.), The social construction of technological systems: New directions in the sociology and history of technology (pp. 111-134). Cambridge, MA: MIT Press.

Macnaughten, P., Kearnes, M., \& Wynne, B. (2005). Nanotechnology, governance, and public deliberation: What role for the social sciences? Science Communication, 27, 1-24.

Martin, M. W., \& Schinzinger, R. (1996). Ethics in engineering (3rd ed.). New York: McGraw-Hill.

McDonough, W., \& Braungart, M. (2002). Cradle to cradle: Remaking the way we make things. New York: North Point.

Mitcham, C. (1994a). Engineering design research and social responsibility. In K. S. Shrader-Frechette (Ed.), Research ethics (pp. 153-168). Totowa, NJ: Rowman \& Littlefield.

Mitcham, C. (1994b). Thinking through technology: The path between engineering and philosophy. Chicago: University of Chicago Press.

Mitcham, C. (1999). Why the public should participate in technical decision making. In R. von Schomberg (Ed.), Democratising technology: Theory and practice of a deliberative technology policy (pp. 39-50). Hengelo, the Netherlands: International Centre for Human and Public Affairs.

Mitcham, C. (2003a) Co-responsibility for research integrity. Science and Engineering Ethics, 9(2), 273-290.

Mitcham, C. (2003b). Professional idealism among scientists and engineers: A neglected tradition in STS studies. Technology in Society, 25, 249-262.

Mitcham, C., \& Frodeman, R. (2004). New dimensions in the philosophy of science: Toward a philosophy of science policy. Philosophy Today, 48(5/5), 9-14.

Newberry, B. (in press). Are engineers instrumentalists? Technology in Society.

Nordan, M. M. (2005, November 17). Nanotech environmental, health, and safety (EHS) risks: Action needed (Testimony before the U.S. House of Representatives Committee on Science). Available at http://www.house.gov/science/hearings/full05/nov\%2017/Nordan.pdf

Pielke, R. A., Jr., \& Byerly, R., Jr. (1998). Beyond basic and applied. Physics Today, 51(2), 41-46.

Rejeski, D. (2005). Introduction. In M. Rodemeyer, D. Sarewitz, \& J. Wilsdon (Eds.), The future of technology assessment (p. 5). Washington, DC: Woodrow Wilson International Center for Scholars. Available at http://www.wilsoncenter.org/news/ docs/techassessment.pdf

Roco, M., \& Bainbridge, S. (2002). Converging technologies for improving human performance: Nanotechnology, biotechnology, information technology and cognitive science. Arlington, VA: National Science Foundation.

Rip, A. (2002). Co-evolution of science, technology and society. Expert review for Bundesministerium Bildung und Forchung Förderinitiative Politik, Wissenschaft und Gesellschaft, as managed by Berlin-Brandenburgische Akademie der Wissenschaften.

Rip, A. (2006). A co-evolutionary approach to reflexive governance-and its ironies. In J. Voss, D. Bauknecht, \& R. Kemp (Eds.), Reflexive governance for sustainable development (pp. 82-100). Cheltenham, UK: Edward Elgar.

Rip, A., \& Kemp, R. (1998). Technological change. Resources and Technology, 2, 327-399.

Rip, A., Misa, T. J., \& Schot, J. (1995). Managing technology in society: The approach of constructive technology assessment. London: Pinter.

Rodemeyer, M. (2005). Back to the future: Revisiting OTA ten years later. In M. Rodemeyer, D. Sarewitz, \& J. Wilsdon (Eds.), The future of technology assessment (pp. 6-13). Washington, DC: Woodrow Wilson International Center for Scholars. Available at http://www.wilsoncenter.org/news/docs/techassessment.pdf

Sarewitz, D. (1996). Frontiers of illusion: Science, technology and politics of progress. Philadelphia: Temple University Press.

Sarewitz, D. (2005). This won't hurt a bit: Assessing and governing rapidly advancing technologies in a democracy. In M. Rodemeyer, D. Sarewitz, \& J. Wilsdon (Eds.), The future of technology assessment (pp. 14-21). Washington, DC: Woodrow Wilson International Center for Scholars. Available at http://www.wilsoncenter.org/news/docs/techassessment.pdf

Sarewitz, D., \& Woodhouse, E. (2003). Small is powerful. In A. Lightman, D. Sarewitz, \& C. Desser (Eds.), Living with the genie: Essays on technology and the quest for human mastery (pp. 63-83). Washington DC: Island.

Schot, J. (1992). Constructive technology assessment and technology dynamics: The case of technology dynamics. Science, Technology, and Human Values, 17, 36-56.

Schot, J., \& Rip, A. (1997). The past and future of constructive technology assessment. Technological Forecasting and Social Change, 54, 251-268.

Sclove, R. E. (1995). Democracy and technology. New York: Guilford.

Shrader-Frechette, K. S. (1991). Risk and rationality: Philosophical foundations for populist reforms. Berkeley: University of California Press.

Shrader-Frechette, K. S. (1995). Technology assessment. In W. Reich (Ed.), Encyclopedia of bioethics (2nd rev. ed., Vol. 5, pp. 2484-2490). New York: Macmillan.

Snow, C. P. (1959). The two cultures and the scientific revolution. New York: Cambridge University Press.

Thompson, E. P. (1968). The making of the English working class (New ed.). Harmondsworth, UK: Penguin.

21st Century Nanotechnology Research and Development Act, Public Law 108-153 (2003).

U.S. House of Representatives, Committee on Science. (2003). Report 108-89 (S. Boehlert, U.S. House of Representatives, 108th Congress, 1st Session). Washington, DC: Author. 
U.S. Senate, Committee on Commerce, Science, and Transportation (1989). Human Genome Initiative hearing. Washington, DC: Author.

Van den Ende, J., Mulder, K., Knot, M., Moors, E., \& Vergragt, P. (1998). Traditional and modern technology assessment: Toward a toolkit—A research methodology and learning strategy for social impact assessment. Technological Forecasting and Social Change, 58(1), 5-21.

Van de Poel, I. (2000). On the role of outsiders in technical development. Technology Analysis \& Strategic Management, 12(3), 383-397.

Vanderburg, W. H. (1995). Preventive engineering: Strategy for dealing with negative social and environmental implications of technology. Journal of Professional Issues in Engineering Education and Practice, 121(3), 155-160.

Vincenti, W. G. (1990). What engineers know and how they know it. Baltimore, MD: Johns Hopkins University Press.

Wilsdon, J. (2005). Paddling upstream: New currents in European technology assessment. In M. Rodemeyer, D. Sarewitz, \& J. Wilsdon (Eds.), The future of technology assessment (pp. 2229). Washington, DC: Woodrow Wilson International Center for Scholars. Available at http://www.wilsoncenter.org/news/docs/ techassessment.pdf

Wilsdon, J., \& Willis, R. (2004). See-through science: Why public engagement needs to move upstream. London: Demos.

Wilsdon, J., Wynne, B., \& Stilgoe, J. (2005). The public value of science: Or how to ensure that science really matters. London: Demos.

Winner, L. (1986). The whale and the reactor: A search for limits in an age of high technology. Chicago: University of Chicago Press.

Winston, R. (2005). Foreword. In J. Wilsdon, B. Wynne, \& J. Stigloe (Eds.), The public value of science: Or how to ensure that science really matters (pp. 11-13). London: Demos.

Erik Fisher is a postdoctoral research fellow at the Center for Nanotechnology in Society and the Consortium for Science, Policy, and Outcomes at Arizona State University. He has held faculty appointments at the Center for Science and Technology Policy Research, the Engineering Management Program, and the Farrand and Herbst Humanities Programs at the University of Colorado at Boulder, where he served as humanities advisor for the College of Engineering and Applied Science. His interests are in science and technology policy research and interdisciplinary connections between sociohumanistic and technoscientific modes of thought, practice, and knowledge production. His research has appeared in Science and Public Policy, Technology in Society, and Philosophy
Today. He holds a PhD in environmental studies, a graduate certificate in science and technology policy, an MA in classics from the University of Colorado at Boulder, and a BA in philosophy and mathematics from St. John's College in Annapolis, Maryland.

Roop L. Mahajan is director of the Institute for Critical Technology and Applied Science at Virginia Tech. He has expertise in nanotechnology, bio-micro-electro-mechanical systems, cellular engineering microsystems, artificial neural networks, humanistic engineering, thermal sciences, and solar energy. He founded the Center for Advanced Manufacturing and Packaging for Microwave, Optical and Digital Electronics, a National Science Foundation Industry/ University Cooperative Research Center. He is also the founder of MicroElectronic Devices in Cardiovascular Applications. He has received numerous awards, including the American Society of Mechanical Engineers (ASME) 2003 Charles Russ Richards Memorial Award for outstanding achievement in mechanical engineering and the 2002 ASME Heat Transfer Memorial Award. He was a research leader and supervisor for AT\&T Bell Labs and is an ASME fellow and a Bell Labs fellow. He holds a PhD in mechanical engineering from Cornell University.

Carl Mitcham is a professor of liberal arts and international studies at the Colorado School of Mines. One of the leading American philosophers of technology, with an emphasis on ethics, he has worked to promote ethical reflection on technology at Brooklyn Polytechnic University, Pennsylvania State University, and the Colorado School of Mines. Among his recent publications is the four-volume Encyclopedia of Science, Technology, and Ethics (Macmillan Reference, 2005), for which he served as editor-in-chief. He is also the editor of Philosophy of Technology Reader, Philosophy and Technology II, and Ethics and Technology and is the author of Technology and Religion, Thinking Through Technology, Social and Philosophical Construction of Technology, and Engineering Ethics. He is a former philosophy professor and director of the Science-TechnologySociety Program at Pennsylvania State University; founding director of the Philosophy and Technology Studies Center at Polytechnic University, New York; and president of the Society for Philosophy and Technology. He holds a PhD in philosophy from Fordham University. 